Portland State University

PDXScholar

2015

\title{
Will You Value Me and Do I Value You? The Effect of Phenotypic Racial Stereotypicality on Organizational Evaluations
}

Kimberly Barsamian Kahn

Portland State University, kimbkahn@pdx.edu

Miguel M. Unzueta

University of California, Los Angeles

Paul G. Davies

University of British Columbia

Aurelia T. Alston

Portland State University

J. Katherine Lee

Portland State University

Follow this and additional works at: https://pdxscholar.library.pdx.edu/psy_fac

Part of the Social Psychology Commons

Let us know how access to this document benefits you.

\section{Citation Details}

Kahn, Kimberly Barsamian; Unzueta, Miguel M.; Davies, Paul G.; Alston, Aurelia T.; and Lee, J. Katherine, "Will You Value Me and Do I Value You? The Effect of Phenotypic Racial Stereotypicality on Organizational Evaluations" (2015). Psychology Faculty Publications and Presentations. 13.

https://pdxscholar.library.pdx.edu/psy_fac/13

This Post-Print is brought to you for free and open access. It has been accepted for inclusion in Psychology Faculty Publications and Presentations by an authorized administrator of PDXScholar. Please contact us if we can make this document more accessible: pdxscholar@pdx.edu. 


\section{Accepted Manuscript}

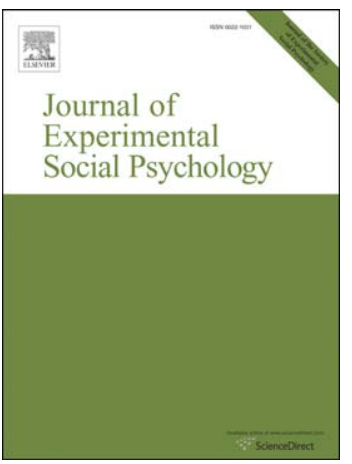

Will you value me and do I value you? The effect of phenotypic racial stereotypicality on organizational evaluations

Kimberly Barsamian Kahn, Miguel M. Unzueta, Paul G. Davies, Aurelia T. Alston, J. Katherine Lee

PII:

S0022-1031(15)00030-X

DOI:

doi: 10.1016/j.jesp.2015.03.008

Reference: $\quad$ YJESP 3302

To appear in: Journal of Experimental Social Psychology

Received date: 29 January 2014

Revised date: $\quad 18$ March 2015

Please cite this article as: Kahn, K.B., Unzueta, M.M., Davies, P.G., Alston, A.T. \& Lee, J.K., Will you value me and do I value you? The effect of phenotypic racial stereotypicality on organizational evaluations, Journal of Experimental Social Psychology (2015), doi: 10.1016/j.jesp.2015.03.008

This is a PDF file of an unedited manuscript that has been accepted for publication. As a service to our customers we are providing this early version of the manuscript. The manuscript will undergo copyediting, typesetting, and review of the resulting proof before it is published in its final form. Please note that during the production process errors may be discovered which could affect the content, and all legal disclaimers that apply to the journal pertain. 


\section{RUNNING HEAD: PHENOTYPIC STEREOTYPICALITY AND DIVERSITY}

Will you value me and do I value you?

The effect of phenotypic racial stereotypicality on organizational evaluations

Kimberly Barsamian Kahn

Portland State University

Miguel M. Unzueta

University of California, Los Angeles

Paul G. Davies

University of British Columbia

Aurelia T. Alston

Portland State University

J. Katherine Lee

Portland State University

Address correspondence to:

Kimberly Barsamian Kahn

Portland State University

Department of Psychology

PO Box 751

Portland, OR 97207 


\begin{abstract}
This paper investigates whether within-group differences in phenotypic racial stereotypicality (i.e., extent to which individuals possess physical features typical of their racial group) of ingroup members serve as social identity contingency cues for Blacks evaluating organizations. It is hypothesized that Blacks draw information about whether their social identity would be valued based on the represented phenotypic racial stereotypicality of Black organization members. Participants viewed organizations that included high phenotypically stereotypic (HPS) Black (e.g., darker skin tones, broader facial features), low phenotypically stereotypic (LPS) Black, or only White employees. Results confirmed that Black, but not White, evaluators reported more diversity, salary, desire to work, and social identity-related trust toward the HPS, compared to LPS and White, organizations. The relationships between phenotypic racial stereotypicality condition on organizational attractiveness and diversity perceptions were mediated by identity-related trust. Results suggest considering diversity at both the group level and within group level to achieve broader benefits.
\end{abstract}

Keywords: phenotypic racial stereotypicality, race, diversity, social identity, stereotyping 


\section{Will you value me and do I value you?}

\section{The effect of phenotypic racial stereotypicality on organizational evaluations}

In 2004, clothing retailer Abercrombie \& Fitch (A\&F) settled a class-action race and gender discrimination lawsuit in which they agreed to increase diversity by adding more non-White models and employees (Greenhouse, 2004). After the settlement, critics of A\&F noted, while increasing group level diversity in their hires and models, A\&F still featured a "specific type" of minority, selecting lighter-skinned and straight-haired minorities (Noble, 2006; Rodonline, 2005; Critical Race Studies, 2008). These descriptions depict individuals that are lower in phenotypic racial stereotypicality, which is the degree to which individuals possess the typical physical features of their racial group (Kahn \& Davies, 2011; Eberhardt, Davies, Purdie-Vaughns, \& Johnson, 2006; Eberhardt, Goff, Purdie \& Davies, 2004). Although the company increased group level diversity, hiring low phenotypically stereotypic minorities led many minorities to distrust A\&F for not representing diversity to the fullest extent (Noble, 2006; Rodonline, 2005; Critical Race Studies, 2008). A\&F is not alone in such preferences, as other companies have faced backlash from minorities due to their, sometimes explicit, predilections for featuring only light-skinned minorities (e.g., Hardigree, 2012).

We argue that perceptions of racial diversity are not only based on group level representations of minorities, but that the phenotypic racial stereotypicality of group members may also be an important aspect of diversity. We suggest that these within group differences in perceived phenotypic racial stereotypicality will serve as social identity contingency cues for minorities and affect their organizational evaluations. 


\section{Racial diversity as social identity contingency cues}

Racial diversity, traditionally defined as representation or inclusion of racial group members at the group level, can have benefits for both individual group members as well as organizations as a whole. These benefits can include increased sales, broader clientele, and higher levels of productivity (Herring, 2009; Kochan et al., 2003; Rhodes \& Packel, 2010; Richard, 2001; however, see also Mannix \& Neale, 2005). To achieve racial diversity, organizations must attract, and keep, minority employees. The perceived racial diversity of an organization is important to potential minority applicants and increases the likelihood that a minority individual will join an organization (Avery, 2003; Murphy, Steele, \& Gross, 2007; Thomas \& Wise, 1999).

Group level racial diversity is important to minorities because it serves as a social identity contingency cue to potential minority group members. Social identity contingencies are cues in the environment that influence perceptions regarding whether an individual's social identity will be accepted in a given situation (Purdie-Vaughns, Steele, Davies, Ditlmann, \& Crosby, 2008). Because they are a member of a negatively stereotyped group, this acceptance may be highly variable and situationally dependent for minorities. Social identity contingencies, such as the presence of fellow racial group members and inclusive organizational diversity statements, increase minorities' social identity-related trust and comfort with an organization (Purdie-Vaughns et al., 2008). The trust and comfort secures their identity in the face of identity threat or uncertainty, allowing them to feel that they could be themselves at the organization.

Minority and majority group members are differentially influenced by represented racial diversity and other minority identity-related cues in a setting. For racial minorities, 
social identity cues involving perceived racial diversity affect the extent to which racial minorities view an organization as a trustworthy and desirable place to work (PurdieVaughns et al., 2008; see also Bauman, Trawalter, \& Unzueta, 2014). Minorities also report greater trust and comfort toward organizations that espouse more racially inclusive than restrictive diversity policies (Purdie-Vaughns et al., 2008). Conversely, Whites' were less affected by the number of minority group members employed by the organization compared to minority group evaluators (Purdie-Vaughns et al., 2008; see also Avery, 2003) and perceive more diversity than minorities within the same environment (Mor Barak, Cherin, \& Berkman, 1998). Environmental cues, including physical objects that are closely associated with particular social identities, can also signal identity-related threat for racial minorities and negatively stereotyped groups, while being less influential for majority group members (Cheryan, Plaut, Davies, \& Steele, 2009). Further, White perceivers are primarily sensitive to the total raw number or hierarchical representation of minority employees in the organization, whereas minority perceivers assess organizational diversity using both the total number of minority employees in combination with their location in the organization's hierarchy (Unzueta \& Binning, 2012; Binning \& Unzueta, 2013). These structural cues may signal to minorities their potential for advancement and lead to differential social identityrelated trust with the organization.

\section{Perceived phenotypic racial stereotypicality as a social identity contingency cue}

Might perceived phenotypic racial stereotypicality of ingroup members also serve as a social identity contingency cue for Blacks evaluating an organization? Perceived phenotypic racial stereotypicality increases racial stereotyping by perceivers, such that 
high phenotypically stereotypic minorities are targeted by more stereotyping and prejudice than those lower in phenotypic stereotypicality (Blair, Judd, \& Chapleau, 2004; Blair, Judd, \& Fallman, 2004; Blair, Judd, Sadler, \& Jenkins, 2002; Eberhardt et al., 2006; Eberhardt et al., 2004; Kahn \& Davies, 2011; Livingston \& Brewer, 2002;

Maddox, 2004). Minorities are also aware of their own phenotypic stereotypicality levels and the associated difference in treatment it entails (Kahn, 2010). Darker-skinned minorities report experiencing more discrimination than lighter-skinned group members (Klonoff \& Landrine, 2000). Highly phenotypically stereotypic Blacks are also more sensitive to social identity-related threats based on race, including stereotype threat (Kahn, 2010; Kahn, Lee, Renauer, Henning, \& Stewart, 2014).

Blacks' sensitivity to identity-related threats leads to our hypothesis that Blacks will use the phenotypic racial stereotypicality of existing ingroup members as a social identity contingency cue when evaluating an organization. Blacks may be distrustful of organizations in which the sole Black ingroup members are low in phenotypic stereotypicality. We hypothesize that the racial phenotypic stereotypicality of Blacks will be less influential on Whites' evaluations, due to the lack of information that these cues provide about their own group's potential treatment.

To test the hypotheses, Black and White participants evaluated organizations that featured highly phenotypically stereotypic (HPS) Black employees, low phenotypically stereotypic (LPS) Black employees, or only White employees. We predict that Black, but not White evaluators, will perceive the HPS, compared to the LPS, organization as more diverse, espouse more social identity-related trust and comfort, report a higher potential salary, and view the organization as more attractive place to work. Because social 
identity contingency cues increase social identity-related trust and comfort (PurdieVaughns et al., 2008), we predict that trust and comfort will mediate the effect of the organization's represented phenotypic racial stereotypicality on our key outcomes: organizational attractiveness, racial diversity perceptions, and predicted salary.

Finally, we examine whether these effects are moderated by Blacks' level of racial identification and own level of phenotypic racial stereotypicality. The more central one's racial group is to their social identity, the more influential social identity contingency cues may be on their evaluations. Similarly, Black evaluators' level of racial phenotypic stereotypicality may increase their reliance on and the importance of the represented phenotypic stereotypicality levels of the presented employees, as the LPS company could signal the company's exclusion of their social identity. Lack of moderation by these two participant level identity-related cues and beliefs would suggest that this process is present for Blacks more broadly.

\section{Method}

\section{Participants and Design}

One hundred fifty six participants (60 Black and 96 White, 112 female and 44 male) took part in the study for partial course credit or $\$ 3.00$. Participants were recruited from a database of working individuals and students in Los Angeles. The experiment was a 2 (Participant Race: Black vs White) x 3 (Employee Phenotypic Racial Stereotypicality: High vs. Low vs. White only) between subjects design. Black and White participants did not significantly differ on level of education, political attitudes, English as a first language, gender, or age.

\section{Materials}


Organization website. Three company websites were created for the fictitious Crestfield Consulting firm: a high phenotypically stereotypic (HPS) Black employee version, a low phenotypically stereotypic (LPS) Black employee version, and a White version (see Appendix). The professional looking websites contained neutral information about the company's mission and were modeled after real consulting websites (e.g., “Crestfield Consulting promotes a vibrant and challenging atmosphere that allows its employees to produce top quality results.").

The three websites varied in the presented phenotypic stereotypicality of two Black employees. The two Black employee photographs in the LPS and HPS sites were altered using Photoshop following racial phenotypic stereotypicality photograph manipulation protocols (e.g., Kahn \& Davies, 2011). The HPS versions received a darker skin tone and more stereotypic features, including a broader nose and thicker lips than the LPS version. By altering the same photographs, subtle individual differences about the featured person are controlled. In the White version, the central photograph of a Black employee was replaced with a White employee, and a second Black employee was cropped out of a group image. Images were pretested for attractiveness and racial group membership.

Company perceptions survey. Participants answered questions about the company as a potential applicant. Items were asked on a 7-point Likert Scale, from 1=Strongly Disagree to 7=Strongly Agree, unless otherwise indicated.

Diversity perceptions. Four items measured impressions of racial diversity at Crestfield Consulting (adapted from Unzueta \& Binning, 2012), including “Crestfield Consulting has a high level of racial diversity," $\alpha=.52$. 
Social identity-related trust and comfort. Eleven items measured participants' social identity-related trust and comfort with Crestfield Consulting using the PurdieVaughns et al. (2008) measure. The scale loads onto one factor with example items, "I think I could be myself at a company like Crestfield Consulting," and "I think that my values and the values of Crestfield Consulting are very similar, $(\alpha=.93)$.

Organizational attractiveness. Three items measured participants' desire to work at Crestfield Consulting, including "Crestfield Consulting is attractive to me as a potential employer," $\alpha=.93$ (Avery, 2003; Highhouse, Lievens, \& Sinar, 2000; Perkins, Thomas, \& Taylor, 2000).

Estimated salary. Participants' perceived monetary value to the organization was measured by the item, "If you were hired at Crestfield Consulting, what do you think your annual salary would be?" ( $\$ 20,000$ to $\$ 140,000$ in $\$ 20,000$ increments).

Participant phenotypic racial stereotypicality. Participants received a description of phenotypic racial stereotypicality and were asked 3 items: "How stereotypic do you/people from other racial groups/people from your racial group think you physically look?” $\alpha=.95$, (Kahn, 2010).

Racial/ethnic identification. Four items from the identity subscale of the Collective Self-Esteem Scale (Luhtanen \& Crocker, 1992) were used to measure racial identification (e.g., "The racial group I belong to is an important reflection of who I am," $\alpha=.76)$.

Demographics. Demographic information was collected, including race, gender, age, education, English as a first language, and political attitudes.

\section{Procedure}


Participants received an email invitation to the online survey. Upon agreeing to participate, participants were randomly assigned regardless of race to one of three company conditions (HPS, LPS, or White), and were told to evaluate the company as a potential employee. The company website was then presented for 5 minutes, consisting of the company information and employee pictures. Next, participants completed the company perceptions survey. Participants were then debriefed, thanked, and credited for participation.

\section{Results}

Separate between-subjects ANOVAs were run using a set of orthogonal contrasts to test hypotheses regarding within group and group based effects of organizational diversity. Examining the primary hypothesis that Black, but not White, participants would be sensitive to the phenotypic stereotypicality differences of the presented organizations, Contrast 1 tests participants' within group diversity distinctions between the HPS and LPS conditions, $(\mathrm{HPS}=+1 \mathrm{LPS}=-1 \mathrm{WHT}=0)$. Contrast $2(\mathrm{HPS}=+1$ LPS $=+1$ WHT $=-2$ ) tests the participants' distinction between group based racial diversity (HPS or LPS) compared to no racial diversity (WHT). Condition means, standard deviations, and pairwise comparisons are listed in Table 1.

\section{Perceived racial diversity}

The omnibus ANOVA revealed a significant main effect of participant race, $F(1$, $147),=12.38, p<.001$, partial $\eta^{2}=.08$, and a significant main effect of phenotypic stereotypicality condition, $F(2,147)=21.83, p<.001$, partial $\eta^{2}=.23$, which were qualified by the predicted phenotypic stereotypicality condition $\mathrm{x}$ participant race interaction on racial diversity, $F(2,147)=4.08, p=.02$, partial $\eta^{2}=.05$. The within group 
contrast (Contrast $1, \mathrm{HPS}=+1 \mathrm{LPS}=-1 \mathrm{WHT}=0)$ demonstrated a main effect of Contrast $1, F(1,147)=4.02, p=.047, \eta^{2}=.03$, and a weak trend toward a participant race $\mathrm{x}$ Contrast 1 interaction, $F(1,147)=2.10, p=.15$, partial $\eta^{2}=.01$. Despite the nonsignificant interaction, based on our apriori hypotheses, we tested Contrast 1 for each participant race. Black participants reported significantly higher perceived racial diversity in the HPS compared to the LPS condition, mean difference $=.61, F(1,54)=$ 3.87, $p=.05$. As predicted, White participants did not differ in their perceptions between the HPS and LPS conditions, mean difference $=.10, F(1,93)=.25, p=.62$. In light of the non-significant interaction, these results should be interpreted with caution.

Contrast 2, testing the participants' distinction between group based diversity (HPS and LPS) organizations compared to the non-diverse organization (WHT), revealed a significant main effect of Contrast $2, F(1,147)=38.55, p<.001$, partial $\eta^{2}=.21$, qualified by a participant race $\mathrm{x}$ Contrast 2 interaction, $F(1,147)=6.35, p=.01$, partial $\eta^{2}=.04$. While both White and Black participants reported more diversity in the diverse organizations than the non-diverse organization [Black: mean difference $=1.17, F(1,54)=$ 4.87, $p=.03$; White: mean difference $=2.78, F(1,93)=52.31, p<.001]$, White participants made a stronger differentiation in racial diversity between the diverse organizations and the non-diverse organization than Black participants.

\section{Trust and comfort}

The ANOVA confirmed a main effect of phenotypic stereotypicality condition, $F(2,147)=4.96, p=.01$, partial $\eta^{2}=.06$, qualified by the predicted significant phenotypic stereotypicality condition x participant race interaction on trust and comfort, $F(2,147)=3.12, p=.047$, partial $\eta^{2}=.04$, see Figure 1 . Contrast code analyses indicated 
only a significant Participant Race x Contrast 1 interaction, $F(1,147)=5.54, p=.02$, partial $\eta^{2}=.04$, where Black participants reported significantly more trust in the HPS organization than the LPS organization, mean difference $=.79, F(1,54)=6.27, p=.02$, while White participants reported non-significant differences between the HPS and LPS organizations, mean difference $=-.18, F(1,93)=.51, p=.48$.

Examining the group based diversity effects (Contrast 2), there was a significant main effect of Contrast $2, F(1,147)=7.35, p=.01$, partial $\eta^{2}=.05$, such that participants trusted the diverse companies more than the non-diverse company. The participant race $\mathrm{x}$ Contrast 2 effect was not significant, $F(1,147)=.37, p=.35$, partial $\eta^{2}$ $=.01$.

\section{Estimated salary}

Assessing their perceived monetary value to the company, the ANOVA found a significant main effect of phenotypic stereotypicality condition, $F(2,147)=4.88, p=.01$, partial $\eta^{2}=.06$, which was qualified by a marginal phenotypic stereotypicality condition $\mathrm{x}$ participant race interaction on expected salary, $F(2,147)=2.72, p=.07$, partial $\eta^{2}=$ .04. As predicted, there was a significant participant race $\mathrm{x}$ Contrast 1 interaction, $F(1$, $147)=5.42, p=.02$, partial $\eta^{2}=.04$. Black participants indicated a higher potential salary in HPS compared to the LPS company, mean difference $=.94, F(1,54)=6.62, p=$ .01. Whites did not differ in their salary expectations between the HPS and LPS companies, mean difference $=-.13, F(1,93)=.23, p=.63$.

Testing the group based diversity effects, there was a significant main effect of Contrast $2, F(1,147)=6.29, p=.01$, partial $\eta^{2}=.04$, and a non-significant participant 
race $x$ Contrast 2 effect, $F(1,147)=.05, p=.83$, partial $\eta^{2}<.001$. Participants reported higher expected salary in the diverse companies than the non-diverse company.

\section{Organizational attractiveness}

ANOVA results confirmed a significant main effect of participant race, $F(1,147)$ $=7.40, p=.01$, partial $\eta^{2}=.05$, which was qualified by a phenotypic stereotypicality condition x participant race interaction on organizational attractiveness, $F(2,147)=3.52$, $p=.03$, partial $\eta^{2}=.05$. As predicted, there was a significant participant race $\mathrm{x}$ Contrast 1 interaction, $F(1,147)=7.02, p=.01$, partial $\eta^{2}=.05$. Black participants indicated a greater desire to work at the HPS company than the LPS company, mean difference = $1.31, F(1,54)=5.83, p=.02$. White participants did not differ in their desire to work for the HPS or LPS organizations, mean difference $=-.40, F(1,93)=1.16, p=.28$.

Group diversity level analyses showed a marginal main effect of Contrast 2, $F(1$, $147)=2.92, p=.09$, partial $\eta^{2}=.02$, in which participants tended to find the diverse companies more attractive than the non-diverse company. The participant race $\mathrm{x}$ Contrast 2 effect was not significant, $F(1,147)<.001, p=.99$, partial $\eta^{2}<.001$.

\section{Social identity-related trust mediation}

In line with prior research (Purdie-Vaughns et al., 2008), we hypothesized that social identity-related trust would be a key mediator of the relationship between organizational phenotypic stereotypicality condition and our dependent variables of interest: organizational attractiveness, expected salary, and diversity perceptions. ${ }^{1}$ Regression analyses tested for mediation using the identified contrast codes (Baron \& Kenny, 1986). Because the phenotypic stereotypicality condition (Contrast 1) did not 
affect Whites perceptions of organizational attractiveness, salary, or diversity, mediation analyses are not appropriate for the White participants.

For Black participants, the relationship between the phenotypic stereotypicality condition (Contrast 1) and organizational attractiveness was fully mediated by trust, controlling for Contrast 2. As Figure 2 illustrates, for Blacks, controlling for Contrast 2, Contrast $1(\mathrm{HPS}=+1 \mathrm{LPS}=-1 \mathrm{WHT}=0)$ was a significant predictor of trust $(b=.40$, se $=$ $\left..16, p=.02, r^{2}=.13\right)$. Trust positively predicted organizational attractiveness, controlling for Contrasts 1 and $2\left(b=1.23, s e=.16, p<.001, r^{2}=.58\right)$. With the addition of trust in the model, controlling for Contrast 2, Contrast 1 was no longer a significant predictor of organizational attractiveness, $\left(b=.65, \mathrm{se}=.27, \mathrm{p}=.02, r^{2}=.12\right.$ to $b=.17, \mathrm{se}=.20, p=$ $\left..41, r^{2}=.58\right)$. As phenotypic stereotypicality increased in the HPS condition, Black participants reported more trust and comfort with the organization, which was associated with higher organizational attractiveness.

Similarly, regression analyses confirmed that trust mediated the relationship between Contrast 1 and perceived racial diversity, controlling for Contrast 2, for Black participants. Controlling for Contrast 2, Contrast 1 was a significant positive predictor of trust $\left(b=.40, s e=.16, p=.02, r^{2}=.13\right)$. Trust was a significant positive predictor of perceived diversity, controlling for Contrasts 1 and $2\left(b=.25, s e=.13, p=.05, r^{2}=.20\right)$. Finally, the effect of Contrast 1 on perceived diversity became nonsignificant with the addition of trust in the regression, controlling for Contrast $2\left(b=.30, s e=.15, p=.05, r^{2}\right.$ $=.15$ to $\left.b=.20, s e=.16, p=.20, r^{2}=.20\right)$. The HPS organization was associated with an increase in Black participants' trust and comfort, and they reported more racial diversity. 
Finally, trust did not mediate the relationship between Contrast 1 and expected salary for Black participants, controlling for Contrast 2. Trust did not significantly predict expected salary, when controlling for Contrasts 1 and $2(b=.19$, se $=.16, p=$ $.23)$.

\section{Racial Identification and Participant Phenotypic Stereotypicality as Moderators}

We next tested whether Blacks' level of racial identification and own level of phenotypic racial stereotypicality may moderate the relationship between organization stereotypicality condition and the key outcomes. As Whites were not sensitive to the differences in Black phenotypic stereotypicality between conditions, analyses focused on Black participants. Neither racial identification $(p=.28)$ nor participant phenotypic stereotypicality $(p=.92)$ were affected by the organization phenotypic stereotypicality condition manipulation. Racial identification and participants' phenotypic racial stereotypicality were significantly correlated, $r=.35, p=.03$, so the following regression analyses controlled for the opposite predictor.

Participant racial identification moderation. Controlling for level of phenotypic stereotypicality and Contrast 2, the relationship between Contrast 1 and perceived diversity was moderated by Black participants' level of racial identification, $b=.24$, se $=.10, p=.02, r^{2}=.31$, see Figure 3 (Preacher \& Hayes, 2004). Black participants high in racial identification (+1 SD above the mean) were more sensitive to the phenotypic stereotypicality cues between organization stereotypicality conditions, perceiving more diversity in the HPS condition compared to the LPS condition $(b=.57$, se $=.19, p=.01$, CI: .18 to .96). Individuals lower in racial identification (-1 SD below the mean) did not differ between organizational stereotypicality conditions $(b=-.06, s e=.19, p=.76, \mathrm{CI}$ : - 
.45 to .33$)$. Racial identification did not moderate trust $(p=.13)$, expected salary $(p=$ $.49)$ or organizational attractiveness for Black participants $(p=.36)$.

Participant phenotypic stereotypicality moderation. We next examined whether Black participants' own levels of phenotypic racial stereotypicality would moderate their sensitivity to the presented organizational stereotypicality differences (Contrast 1), controlling for Contrast 2 and participants' level of racial identification. Regression analyses indicated that participants' phenotypic racial stereotypicality did not moderate the relationship between organizational stereotypicality and diversity $(p=.17)$, trust $(p=$ $.41)$, expected salary $(p=.25)$, or organizational attractiveness $(p=.15)$.

\section{General Discussion}

Phenotypic racial stereotypicality of ingroup members can serve as a social identity contingency cue that influences Blacks' perceptions of an organization. Blacks, but not Whites, glean information about how their identity will be treated and valued in a group based on the within group differences in phenotypic stereotypicality of Black group members. Blacks expressed more social identity-related trust and comfort in the organization that had high phenotypically stereotypic Black members, compared to the organization with less phenotypically stereotypic Black members, and compared to the organization with only White members. They perceived the HPS company as more diverse, reported higher potential salaries, and had more desire to work in the HPS organizations than the LPS or White organizations. Blacks' social identity-related trust and comfort was the key mechanism, as it mediated their perceptions of organizational attractiveness and diversity. Increased trust in the HPS organization was associated with higher perceptions of racial diversity and how attractive they saw the company as a place 
to work. Trust did not mediate salary perceptions, suggesting that monetary compensation may be less directly tied to identity-related trust than more global perceptions of the workplace environment.

Mirroring the Abercrombie and Fitch aftermath, organizations that only highlighted low phenotypically stereotypic Black group members were evaluated negatively by Blacks. This distrust may be because minorities perceive the LPS organizations as strategically using diversity only in a limited sense, while not truly being inclusive. This potentially dubious motive_of displaying "safer" forms of diversity to check off the "diversity box" — may lead Blacks to negatively evaluate and avoid these organizations.

Examining the group level diversity effects, in light of the significant within group effects, also has important implications. Both Whites and Blacks perceived more diversity, reported more trust, a higher potential salary, and were more interested in working at the group level diverse organizations (HPS and LPS) compared to the nondiverse organization (WHT). Taken at a surface level, one might mistakenly conclude that Blacks and Whites cared similarly regarding company diversity. However, this misinterpretation demonstrates the importance of within group level diversity, as Blacks' overall preference for the group level diverse companies is being driven by their comfort with the HPS company and obscures their discomfort with the LPS company. Examining perceptions at the group level mask these significant within group differences. Definitions of diversity should consider both the group level and within group level representations. 
In line with past research, White participants did not consistently distinguish between the HPS and LPS stereotypic organizations, but did at the group diversity level. Although the phenotypic stereotypicality of Black group members was not seen to reflect on their group's potential treatment, Whites may, however, be sensitive to social identity cues that directly targeted their racial group. Whites, similar to Blacks, did differentiate at the group level—-between the White condition and the Black conditions combined (HPS and LPS) — on perceptions of diversity, trust, expected salary, and organizational attractiveness, with higher perceptions in the racially diverse organizations compared to the White only organization. This finding supports past research showing that numerical diversity or group level diversity is more important for Whites (Unzueta \& Binning, 2012; Binning \& Unzueta, 2013). It also is consistent with the notion that the dominant group may be motivated to define diversity more loosely in order to protect their privileged position (Unzueta, Knowles, \& Ho, 2012; see also Kahn, Ho, Sidanius, \& Pratto, 2009). Indeed, White participants reported more diversity in the diverse companies compared to the non-diverse company than did Blacks. Whites may be motivated to report more diversity than Blacks, and particularly when it is beneficial to their group to do so.

Much of the racial phenotypic stereotypicality research has involved differences in individual person perception based on phenotypic stereotypicality (e.g., Blair et al., 2002; 2004; Eberhardt et al., 2006; Eberhardt et al., 2004; Kahn \& Davies, 2011; Livingston \& Brewer, 2002); none has delved into the effects that phenotypic stereotypicality of group members can have on a larger organization or entity. We show that the influence of these evaluations go beyond the high or low phenotypically 
stereotypic individual being perceived, and can also transmit values to a larger group.

Therefore, the overall influence of these within group differences in phenotypic stereotypicality may be more significant than anticipated.

To better understand the process, research should also hone in on the explicit or implicit nature of phenotypic stereotypicality effects at the organizational level.

Phenotypic stereotypicality has been shown to influence person perception at both the explicit and implicit level (Livingston \& Brewer, 2002; Eberhardt et al., 2004), which suggests that both levels may be involved in the organizational evaluations made in the study. The outrage articulated at Abercrombie for their strategic use of diversity suggests, at least, a partial explicit component. Implicit processes may also be uniquely contributing to these evaluations, signaling distrust at a less conscious level.

Examining the moderations, Blacks' level of racial identification and own level of phenotypic stereotypicality did not consistently moderate the study variables. Because the Black phenotypic stereotypicality cues impart information about how Blacks might be treated, we hypothesized that other group specific variables that involve the strength of group identity or phenotypic appearance may moderate these relationships for Blacks. However, this pattern was not significant in the current data. The only significant moderation was that of racial identification moderating the effect of organizational phenotypic stereotypicality (Contrast 1) on perceptions of diversity, such that highly identified Blacks perceived more diversity in the HPS organization than the LPS organization compared to less identified Blacks. This finding is consistent with research showing that highly identified minorities view diversity in light of its relationship to the ingroup (Unzueta \& Binning, 2012), and that level of group identification moderates 
sensitivity to similar social identity threats, such as stereotype threat (Schmader, 2002;

Spencer, Steele, \& Quinn, 1999). Overall, these non-significant moderation results imply that the effects of racial phenotypic stereotypicality of ingroup members on organizational outcomes may be more broadly applied. Social identity-related trust and comfort appears to be more influential in securing the identity of the Black participants more generally. It is important to note that a larger sample size would provide for a more powerful test of moderation, and thus could help to further understand the role of these participant moderators.

The current study has limitations to be considered as avenues for continued research. First, the results were weaker for diversity, as the predicted interaction between participant race and the stereotypicality manipulation showed a weak trend. The diversity results should therefore be noted with caution. The weaker than anticipated interaction may have been due to the surprisingly low reliability level of the diversity scale. The use of a limited number of Black and White photographs may also limit the generalizability of these findings. The current study focused on Whites' and Blacks' perceptions; continued research should be more inclusive of other racial groups to understand if this process applies to other racial minorities, such as Latinos or Asians. Finally, as the study involved differences in phenotypic stereotypicality for Black men, we cannot make claims regarding the use of gendered racial stereotypicality cues. That is, do Blacks also draw cues about their acceptance from the phenotypic stereotypicality of Black female group members?

To be more inclusive, diversity should be expressed at the within, as well as between, racial group level. Highlighting low stereotypical group members alone may 
signal exclusion of those most physically representative of a given racial category. A\&F and other companies may believe that they are promoting a diverse image; however, if these companies consistently publicize only LPS Blacks and minorities, their efforts may backfire, and lead Blacks and minorities to further distrust the organization. 


\section{References}

Avery, D. R. (2003). Reactions to diversity in recruitment advertising - Are differences in Black and White? Journal of Applied Psychology, 88, 672-679. doi:10.1037/0021-9010.88.4.672

Baron, R. M., \& Kenny, D. A. (1986). The moderator-mediator variable distinction in social psychological research: Conceptual, strategic, and statistical considerations. Journal of Personality and Social Psychology, 51, 1173-1182. doi: 10.1037/0022-3514.51.6.1173

Bauman, C. W., Trawalter, S., \& Unzueta, M. M. (2014). Diverse according to whom? Racial group membership and concerns about discrimination shape diversity judgments. Personality and Social Psychology Bulletin, 40, 1354-1372.

Binning, K. R., \& Unzueta, M.M. (2013). Perceiving ethnic diversity on campus: Group differences in attention to hierarchical representation. Social Psychological and Personality Science, 4, 500-507. doi: 10.1177/1948550612459771

Blair, I. V., Judd, C. M., \& Chapleau, K. M. (2004). The influence of Afrocentric facial features in criminal sentencing. Psychological Science, 15, 674-679. doi: 10.1111/j.0956-7976.2004.00739.x

Blair I.V., Judd C.M., Fallman J.L. (2004). The automaticity of race and Afrocentric facial features in social judgments. Journal of Personality and Social Psychology, 87, 763-778. doi:10.1037/0022-3514.87.6.763

Blair, I. V., Judd, C. M., Sadler, M. S., \& Jenkins, C. (2002). The role of Afrocentric features in person perception: judging by features and categories. Journal of Personality and Social Psychology, 83, 5-25. doi: 10.1037/0022-3514.83.1.5 
Cheryan, S., Plaut, V. C., Davies, P. G., \& Steele, C. M. (2009). Ambient belonging: How stereotypical cues impact gender participation in computer science. Journal of Personality and Social Psychology, 97, 1045-1060. doi: 10.1037/a0016239

Critical Race Studies Second Annual Symposium (2008). Race, Sexuality, and the Law: Abercrombie, Imus and Beyond. University of California, Los Angeles, CA.

Eberhardt, J. L., Davies, P. G., Purdie-Vaughns, V. J., \& Johnson, S. L. (2006). Looking deathworthy: Perceived stereotypicality of Black defendants predicts capitalsentencing outcomes. Psychological Science, 17, 383-386. doi: 10.1111/j.14679280.2006.01716.x

Eberhardt, J. L., Goff, P. A., Purdie, V. J., \& Davies, P. G. (2004). Seeing Black: Race, crime, and visual processing. Journal of Personality and Social Psychology, 87, 876-893. doi: 10.1037/0022-3514.87.6.876

Greenhouse, S. (2004, November 17). Abercrombie \& Fitch bias case is settled . The New York Times. Retrieved from http://www.nytimes.com/2004/11/17/national/17settle.html?_r=0

Hardigree, M. (2012, April 18). Only light-skinned Blacks need apply for Seinfeld Super Bowl ad. Retrieved from http://jalopnik.com/5903028/only-light skinned-blacksneed-apply-for-seinfeld-super-bowl-ad

Herring, C. (2009). Does diversity pay? Race, gender, and the business case for diversity. American Sociological Review, 74, 208-224. doi: 10.1177/000312240907400203 Highhouse, S., Lievens, F., \& Sinar, E. F. (2003). Measuring attraction to organizations. Educational and Psychological Measurement, 63, 986-1001. doi: $10.1177 / 0013164403258403$ 
Kahn, K. B. (2010). The impact of Black stereotypicality on the experiences of stereotype threat. University of California, Los Angeles.

Kahn, K. B., \& Davies, P. G. (2011). Differentially dangerous? Phenotypic racial stereotypicality increases implicit bias among ingroup and outgroup members. Group Processes \& Intergroup Relations, 14, 569-580. doi: $10.1177 / 1368430210374609$

Kahn, K.B, Ho, A., Sidanius, J., \& Pratto, F. (2009). The space between us and them: Perceptions of status differences. Group Processes and Intergroup Relations, 12, 591-604.

Kahn., K.B., Lee. J.K., Renauer, B., Henning, K., \& Stewart, G. (2014). The effects of phenotypic racial stereotypicality and identity threats on racial minorities' attitudes about police. Manuscript submitted for publication.

Keith, V. M., \& Herring, C. (1991). Skin tone and stratification in the Black community. American Journal of Sociology, 97, 760-778.

Klonoff, E. A., \& Landrine, H. (2000). Is skin color a marker for racial discrimination? Explaining the skin color-hypertension relationship. Journal of Behavioral Medicine, 23, 329-338.

Kochan, T., Bezrukova, R.E., Jackson, S., Joshi, A., Jehn, K., Leonard, J., Levine, D., \& Thomas, D. (2003). The effects of diversity on business performance: Report of the diversity research network. Human Resource Management, 42, 3-21. doi: 10.1002/hrm. 10061 
Livingston, R. W., \& Brewer, M. B. (2002). What are we really priming? Cue-based versus category-based processing of facial stimuli. Journal of Personality and Social Psychology, 82, 5-18. doi: 10.1037/0022-3514.82.1.5

Luhtanen, R., \& Crocker, J. (1992). A collective self-esteem scale: Self-evaluation of one's social identity. Personality and Social Psychology Bulletin, 18, 302-318. doi: $10.1177 / 0146167292183006$

Maddox, K. B. (2004). Perspectives on racial phenotypicality bias. Personality and Social Psychology Review, 8, 383-401. doi: 10.1207/s15327957pspr0804_4

Mannix, E. \& Neale, M (2005). What differences make a difference? The promise and reality of diverse teams in organizations. Psychological Science in the Public Interest, 6, 31-55.

Mor Barak, M.E., Cherin, D.A., and Berkman, S. (1998). Organizational and personal dimensions in diversity climate: Ethnic and gender differences in employee diversity perceptions. Journal of Applied Behavioral Sciences, 34, 82-104. doi: $10.1177 / 0021886398341006$

Murphy, M. C., Steele, C. M., \& Gross, J. J. (2007). Signaling threat: How situational cues affect women in math, science, and engineering settings. Psychological Science, 18, 879-885. doi: 10.1111/j.1467-9280.2007.01995.x

Noble, A. (2006, November 6). The Abercrombie \& Fitch look: Still under construction. The Hilltop. Retrieved from http://www.thehilltoponline.com/life-style/theabercrombie-fitch-look-still-under-construction-1.463436\#.UtReauK5_zQ

Perkins, L. A., Thomas, K. M., \& Taylor, G. A. (2000). Advertising and recruitment: Marketing to minorities. Psychology and Marketing, 17, 235-255. doi: 


\subsection{2/(SICI)1520-6793(200003)17:3<235::AID-MAR3>3.0.CO;2-\#}

Preacher, K. J., \& Hayes, A. F. (2004). SPSS and SAS procedures for estimating indirect effects in simple mediation models. Behavior Research Methods, Instruments, and Computers, 36, 717-731.

Purdie-Vaughns, V., Steele, C. M., Davies, P. G., Ditlmann, R., \& Crosby, J. R. (2008).

Social identity contingencies: How diversity cues signal threat or safety for African Americans in mainstream institutions. Journal of Personality and Social Psychology, 95, 308-318. doi: 10.1037/0022-3514.94.4.615

Rhode, D.L., \& Packel, A.K. (2010). Diversity on corporate boards: How much difference does difference make? Rock Center for Corporate Governance, Stanford University Working Paper, no. 89. doi: 10.2139/ssrn.1685615

Richard, O. C. (2001). Racial diversity, business strategy, and firm performance: A resource-based view. Academy of Management Journal, 43, 164-177. doi: $10.2307 / 1556374$

Rodonline. (2005, August 9). Who do we work for? [Web log message]. Retrieved from http://rodonline.typepad.com/rodonline/2005/08/we_diversity.html

Schmader, T. (2002). Gender identification moderates stereotype threat effects on women's math performance. Journal of Experimental Social Psychology, 38, 194-201.

Spencer, S., Steele, C. M., \& Quinn, D. M. (1999). Stereotype threat and women's math performance. Journal of Experimental Social Psychology, 35, 4-28. 
Thomas, K. M., \& Wise, P. G. (1999). Organizational attractiveness and individual differences: Are diverse applicants attracted by different factors? Journal of Business and Psychology, 13, 107-117. doi: 10.1023/A:1022978400698

Unzueta, M. M., \& Binning, K. R. (2012). Diversity is in the eye of the beholder: How concern for the in-group affects perceptions of racial diversity. Personality and Social Psychology Bulletin, 38, 26-38. doi: 10.1177/0146167211418528

Unzueta, M. M., Knowles, E.D., \& Ho, G.C. (2012). Diversity is what you want it to be: How social-dominance motives affect construals of diversity. Psychological Science, 23, 303-309. doi: 10.1177/0956797611426727 
Footnote

${ }^{1}$ Reverse direction mediations, in which the dependent variables (organizational attractiveness, diversity, salary) mediated the effect of organization stereotypicality condition (Contrast 1) on trust and comfort, were also run. Reverse mediations were significant with organizational attractiveness only, and not significant for diversity nor expected salary. Although we cannot rule out the reverse pathway with our crosssectional data, past research supports the social identity contingency cue directly to trust and comfort directional pathway (Purdie-Vaughns et al., 2008). We argue theoretically that these situationally related contingency cues should most proximately affect trust and comfort when participants are evaluating a potential organization, and these perceptions should shape their perceptions of and future involvement with the company. 


\section{Figure Captions}

Figure 1

Perceptions of trust and comfort by phenotypic racial stereotypicality condition for Black and White participants.

Figure 2

Regression coefficients for the relationship between organization stereotypicality condition Contrast 1 (HPS vs. LPS) and organizational attractiveness, controlling for Contrast 2, as mediated by trust and comfort for Black participants.

$* \mathrm{p}<.05 ; * * \mathrm{p}<.001$

Figure 3

Black participants' perceptions of diversity by level of racial identification and organizational stereotypicality condition (Contrast 1), controlling for participant phenotypic stereotypicality and Contrast 2. 
Figures

Figure 1

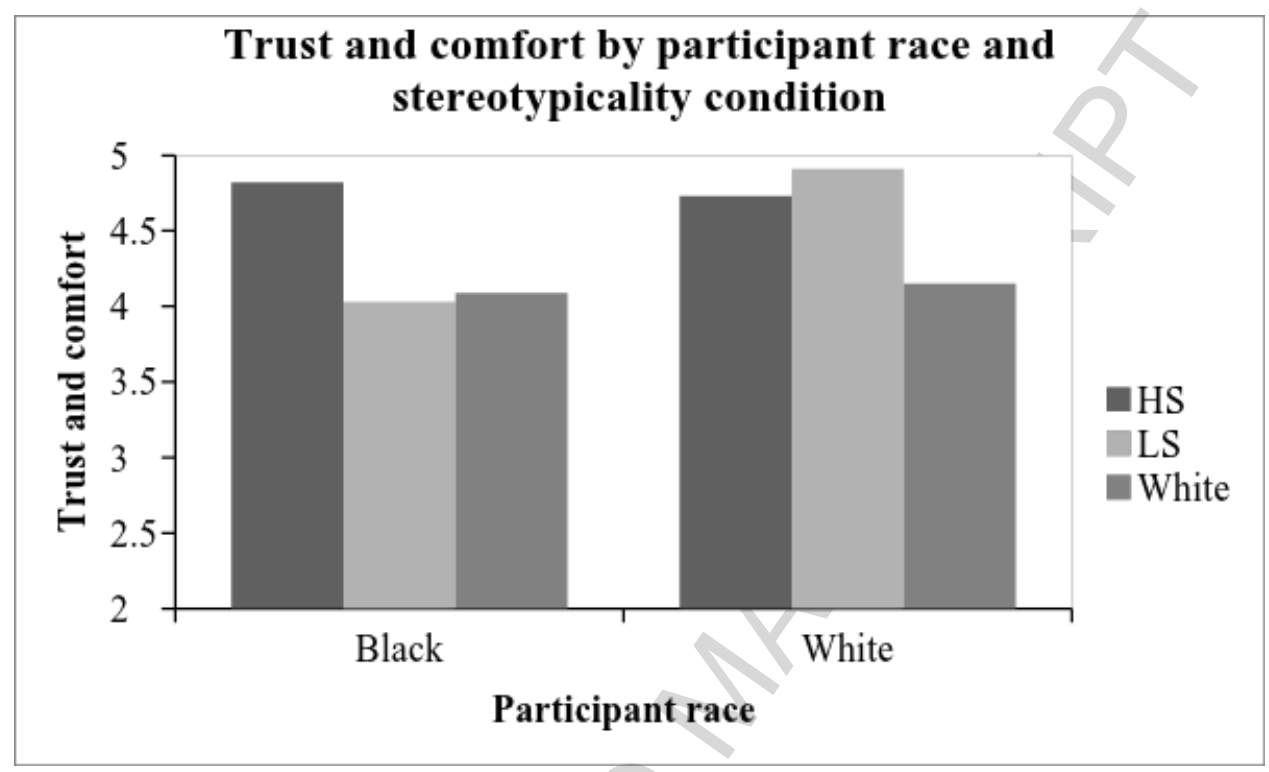

Figure 2 
Figure 3

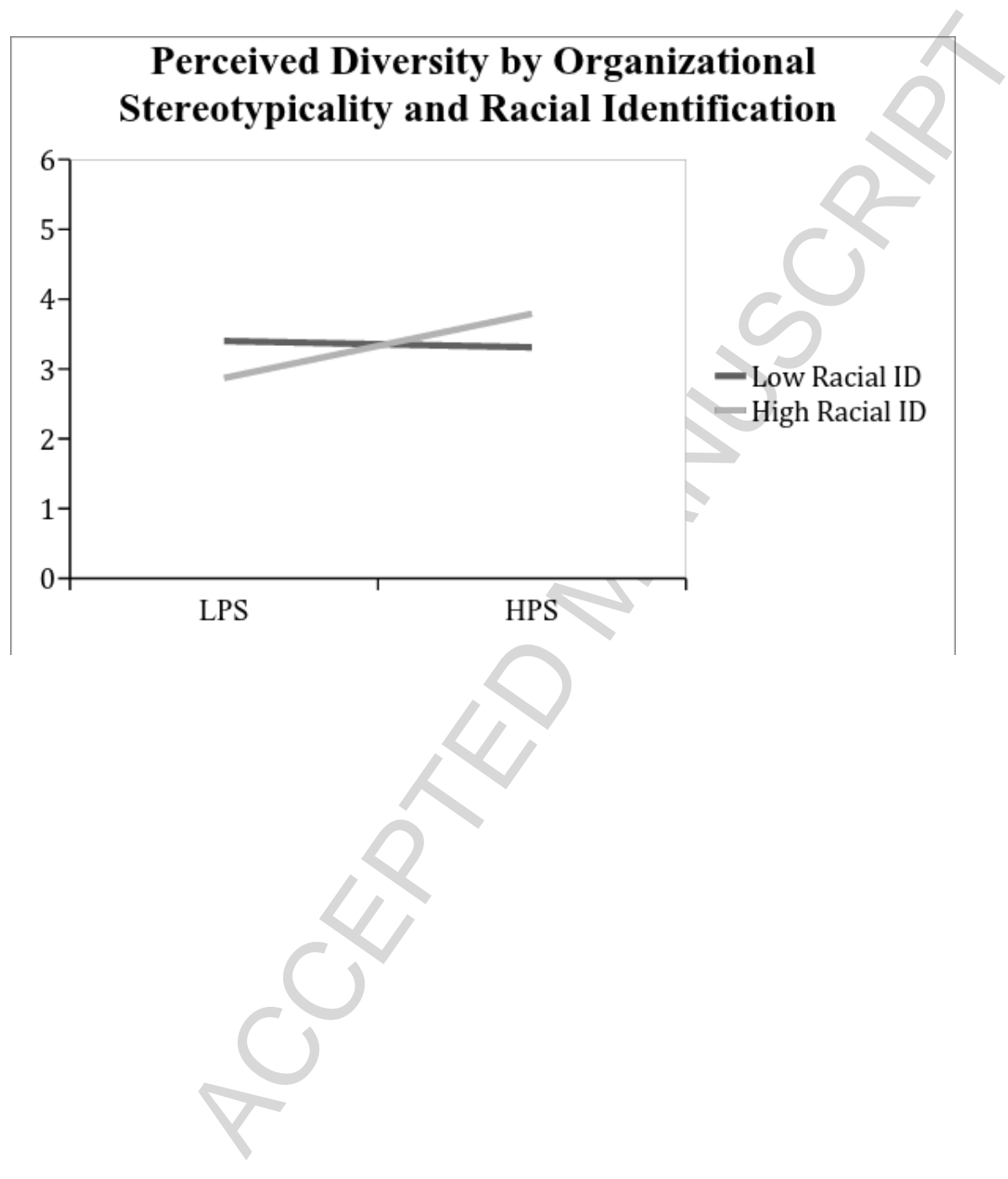


Tables

Table 1.

Means and standard deviations by stereotypicality condition and participant race

\begin{tabular}{|c|c|c|c|c|c|c|}
\hline & \multicolumn{6}{|c|}{ Condition } \\
\hline & \multicolumn{2}{|c|}{ HPS } & \multicolumn{2}{|c|}{ LPS } & \multicolumn{2}{|c|}{ White only } \\
\hline & $\mathrm{M}$ & SD & $\mathrm{M}$ & SD & $\mathrm{M}$ & SD \\
\hline \multicolumn{7}{|l|}{ Diversity } \\
\hline Black & $3.80_{\mathrm{a}}$ & .44 & $3.19_{\mathrm{b}}$ & 1.02 & $2.91_{\mathrm{b}}$ & 1.24 \\
\hline White & $4.32_{\mathrm{a}}$ & .72 & $4.23 \mathrm{a}$ & .73 & $2.89_{\mathrm{b}}$ & 1.06 \\
\hline \multicolumn{7}{|l|}{ Trust and Comfort } \\
\hline Black & $4.82_{\mathrm{a}}$ & & $4.02_{b}$ & 1.09 & $4.09_{b}$ & .81 \\
\hline White & $4.73_{\mathrm{a}}$ & & $4.91_{\mathrm{a}}$ & .91 & $4.15_{\mathrm{b}}$ & 1.37 \\
\hline \multicolumn{7}{|l|}{ Estimated Salary } \\
\hline Black & & 1.34 & $3.06_{b}$ & .83 & $3.05_{b}$ & 1.08 \\
\hline White & & 1.25 & $3.71_{\mathrm{a}}$ & 1.18 & $3.08_{\mathrm{b}}$ & .95 \\
\hline \multicolumn{7}{|l|}{ Org Attractiveness } \\
\hline Black & & 1.95 & $3.11_{\mathrm{b}}$ & 1.56 & $3.21_{\mathrm{b}}$ & 1.34 \\
\hline White & $4.24_{a}$ & 1.54 & $4.64_{\mathrm{a}}$ & 1.52 & $3.95_{\mathrm{a}}$ & 1.63 \\
\hline
\end{tabular}




\section{Appendix}

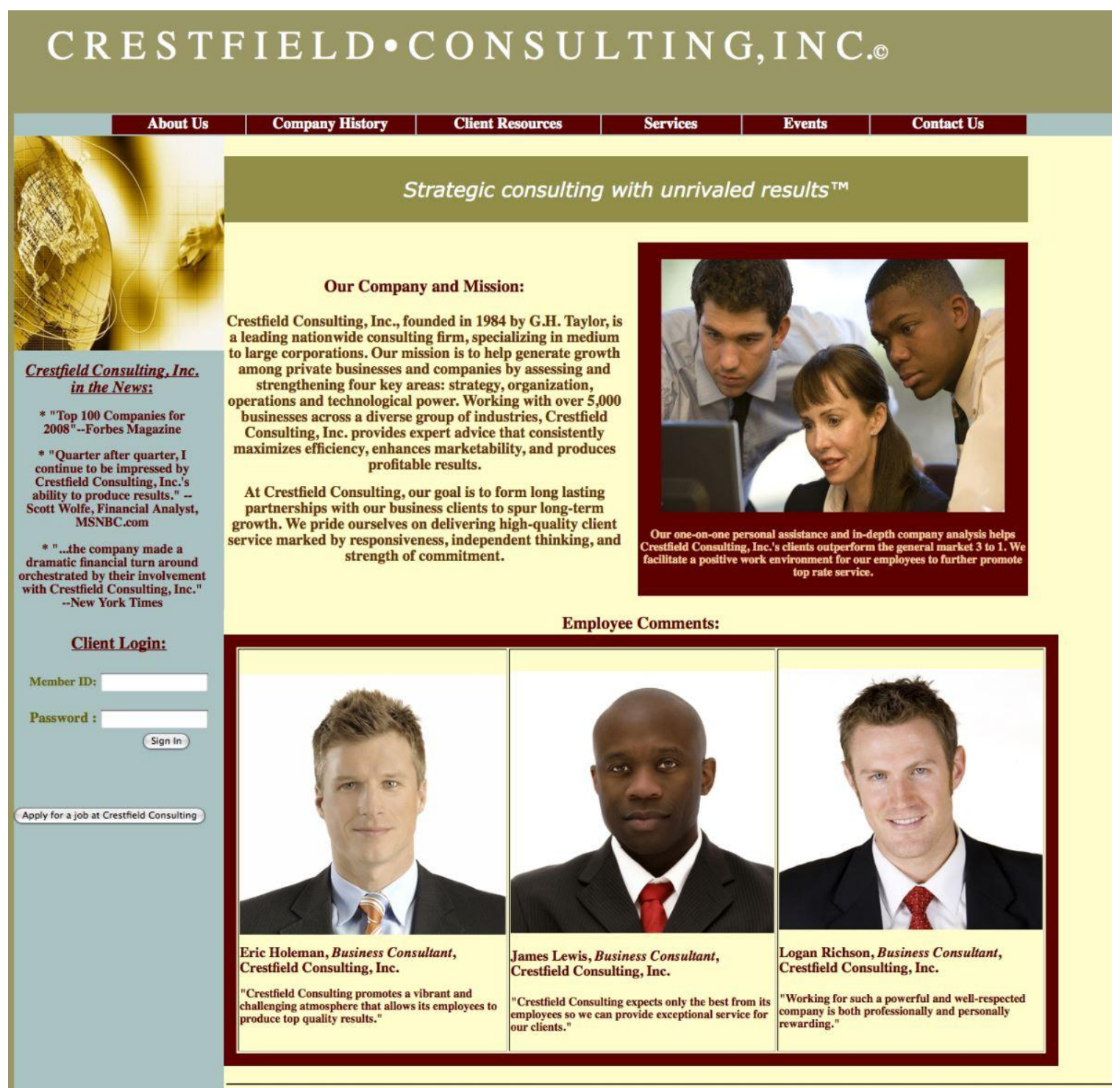

New York | San Francisco | Chicago | Los Angeles | Washington DC | Miami | Boston www.CrestfieldConsulting.com ๑ 2002 | Privacy Policy I All Rights Reserved 


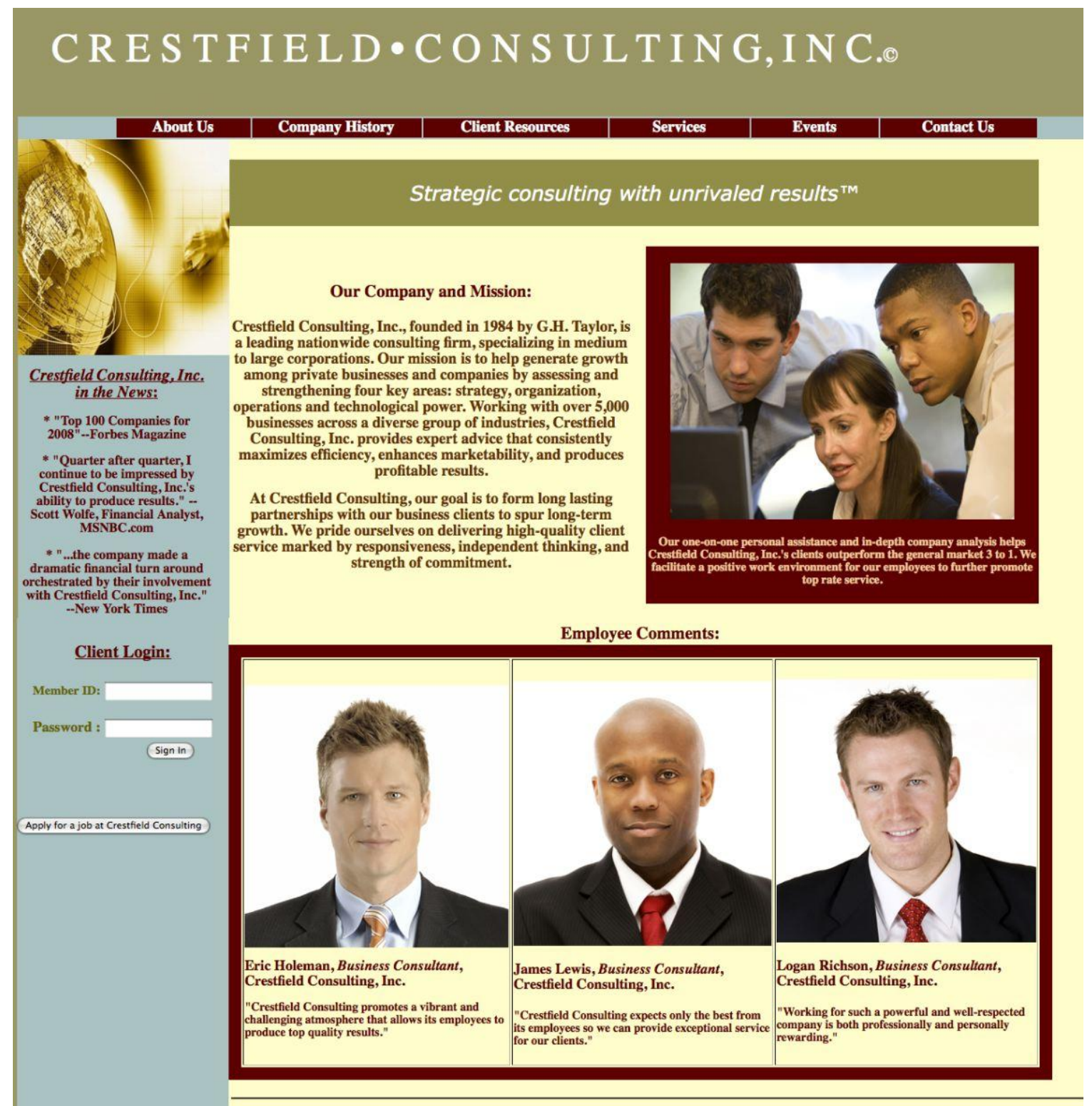

New York | San Francisco | Chicago | Los Angeles | Washington DC | Miami | Boston www.CrestfieldConsulting.com $\odot 2002$ | Privacy Policy $\mid$ All Rights Reserved 


\section{CRESTFIELD•C ONS ULT IN G, IN C.

\begin{tabular}{|c|c|c|c|c|c|c|}
\hline About Us & Company History & Client Resources & Services & Events & Contact Us \\
\hline
\end{tabular}

\section{Strategic consulting with unrivaled results ${ }^{\mathrm{TM}}$}

\section{Our Company and Mission:}

Crestfield Consulting, Inc., founded in 1984 by G.H. Taylor, is a leading nationwide consulting firm, specializing in medium to large corporations. Our mission is to help generate growth among private businesses and companies by assessing and strengthening four key areas: strategy, organization, operations and technological power. Working with over 5,000 businesses across a diverse group of industries, Crestfield Consulting, Inc. provides expert advice that consistently maximizes efficiency, enhances marketability, and produces profitable results.

* "Quarter after quarter, I continue to be impressed by Crestfield Consulting, Inc.'s ability to produce results." -Scott Wolfe, Financial Analyst, MSNBC.com

* "..the company made a dramatic financial turn around orchestrated by their involvement with Crestfield Consulting, Inc." -New York Times

At Crestfield Consulting, our goal is to form long lasting partnerships with our business clients to spur long-term growth. We pride ourselves on delivering high-quality client service marked by responsiveness, independent thinking, and strength of commitment.

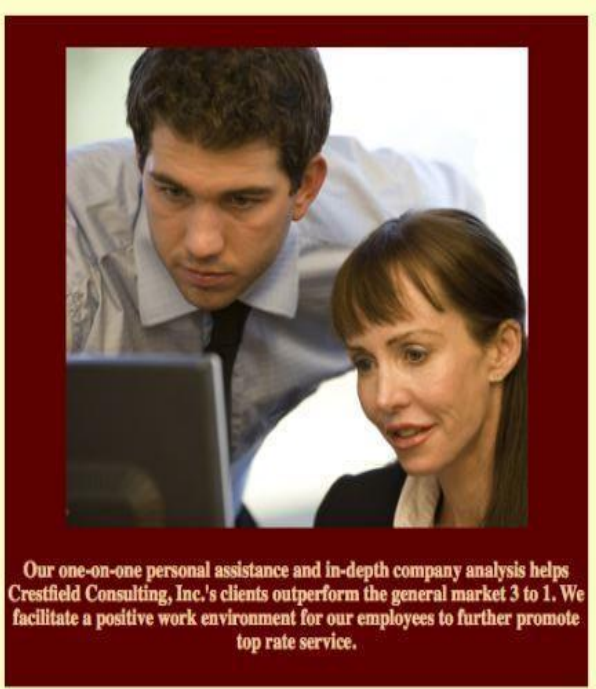

\section{Employee Comments:}
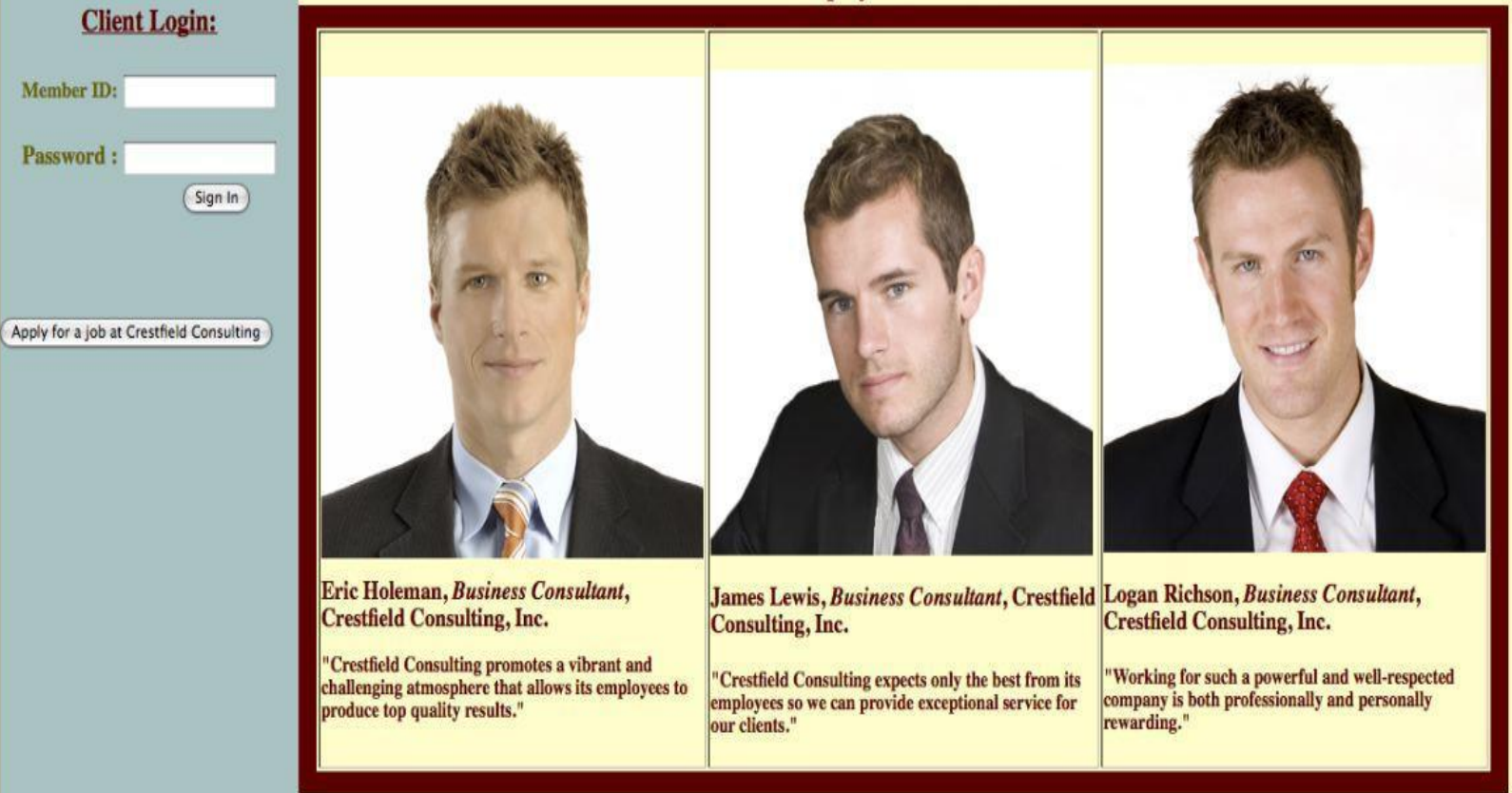

New York | San Francisco | Chicago | Los Angeles | Washington DC | Miami | Boston Www.CrestfieldConsulting.com $\odot 2002$ | Privacy Policy | All Rights Reserved 
High phenotypically stereotypic (HPS, top) low phenotypically stereotypic (LPS, middle), and White only (below) company websites. The wording between the three conditions was identical, such that the differences in the websites were the presence of and phenotypic stereotypicality levels of the two minority employees pictured. 


\section{Highlights}

- Racial stereotypicality is a social identity contingency cue for minorities.

- Blacks expressed trust toward organizations with racially stereotypic members.

- Identity-related trust affected their desire to work in organizations.

- Diversity should be considered at both the within group level and group level. 